\title{
Las emociones del miedo, efectos en las organizaciones. Apuntes para las quejas en la comunidad universitariar
}

The emotions of fear, effects on organizations. Notes for complaints in the university community

\author{
Juan José Vera-Martínez \\ Defensor del Universitario. Universidad de Murcia \\ juverama@um.es
}

\begin{abstract}
Resumen
Es habitual en el funcionamiento de las Defensorías Universitarias que cuando se presentan consultas, quejas o comunicación de hechos que pueden ser objeto de denuncia e inspección, éstas vengan acompañadas de expresiones de aprensión, temor o, inclusive, explícitas reservas por miedo a sufrir represalias. La confidencialidad y neutralidad debidas en las actuaciones no siempre ofrecen la seguridad emocional y real que las personas que se quejan o informan esperan, requieren o necesitan. Las universidades como organizaciones son contexto de manifestación de temores y miedos comunes ante conductas inadecuadas con los efectos perniciosos que muestra la literatura. La cuestión de las posibles represalias hacia informantes y denunciantes y la manera de atender y prevenirlas, detectarlas y perseguirlas mediante definiciones de políticas explícitas y protocolos de actuación es la reflexión que apunta este trabajo.
\end{abstract}

Palabras clave: quejas, miedos, represalias, comportamiento no ético, defensorías universidad

\begin{abstract}
It is common in the normal performance of the University Ombudsmen that when there are queries, complaints or communication of facts that may be the subject of a complaint and inspection, they are accompanied by expressions of apprehension, fear or, even, explicit reservations for fear of suffering reprisals. Due confidentiality and neutrality in proceedings do not always offer the emotional and real security that complainants or reporters expect, require or need. Universities, as organizations, are a context for the manifestation of common fears and fears of inappropriate behavior with the harmful effects shown in the literature. The question of possible reprisals against informants and whistleblowers and the way to attend and prevent them, detect them and prosecute them by means of explicit policy definitions and action protocols is the reflection pointed out in this work.
\end{abstract}

Keywords: complaints, fears, retaliation, unethical behavior, ombudsmen

Sumario. 1-Introducción. 2-Aclarando conceptos básicos. 3-El miedo en las organizaciones. Principales efectos. 4-Miedo en la Universidad como organización. 5-Conclusiones. 6-Referencias.

\footnotetext{
${ }^{1}$ Basado en la ponencia presentada a la Sesión 1: El miedo ante la presentación de una queja: posibles consecuencias por la ausencia de confidencialidad. XI Encuentro Estatal de Defensores Universitarios. CEDU (León, octubre 2018).
} 


\section{Introducción}

El presente trabajo pretende estimular la reflexión sobre los fenómenos y manifestaciones de las emociones del miedo en el contexto organizacional, como entramado en el que se sitúan los temores y reservas de los miembros de la comunidad universitaria a la hora de desempeñar sus funciones, tener un desarrollo educativo o profesional razonable y hacerlo con garantía de salud y bienestar personal y social. Para ello, se suceden varios pasos. Tras un repaso sucinto del campo semántico del miedo en términos convencionales pero también psicológicos y psicobiológicos, que habrá de aportar un lenguaje común y una mejor comprensión de las etiquetas o variables. Seguirá una escueta revisión de los efectos señalados en la literatura sobre el impacto del miedo en las organizaciones y su funcionamiento. Posteriormente extenderemos esa reflexión a la Universidad como organización educativa y científica que implica procesos complejos de gestión.

\section{Aclarando conceptos básicos}

\subsection{Miedo, ansiedad, angustia...}

El miedo es una emoción básica y necesaria que ha servido evolutivamente para garantizar la supervivencia de la persona en entornos potencialmente hostiles. Puede llevar a reacciones como alejarnos de todo aquello que pueda resultar peligroso para nuestra integridad, quedarnos quietos hasta que la amenaza desaparezca o plantarle cara como último recurso cuando no queda otra alternativa. Esta función adaptativa posee un valor innegable para las distintas especies.

El término ansiedad proviene del latín anxietas, refiriendo un estado de agitación, inquietud o zozobra del ánimo. La ansiedad es parte de la existencia humana, todas las personas la sienten en un grado moderado, siendo una respuesta adaptativa. Se le reconoce como una de las sensaciones más frecuentes del ser humano, y se muestra como una emoción complicada y displacentera que se manifiesta mediante una tensión emocional acompañada de un correlato somático. Por lo común, el término ansiedad alude a la combinación de distintas manifestaciones físicas y mentales (a menudo implicando alerta y activación) que no son atribuibles a peligros reales, la cual se manifiesta en forma de crisis (pudiendo llegar al pánico) o bien como un estado persistente y difuso (Sierra, Ortega y Zubeidat, 2003). También se habla de ansiedad como rasgo (de personalidad neurótica, como tendencia recurrente a percibir y reaccionar ansiosamente) o como estado (más situacional, transitorio y variable).

La característica más definitoria de la ansiedad es su carácter anticipatorio, su capacidad de prever o señalar un peligro o amenaza para el individuo, lo que se completa con su función activadora y facilitadora de la capacidad de respuesta del individuo, resultando en un mecanismo biológico adaptativo de protección y preservación ante posibles daños. No obstante, si la ansiedad supera la normalidad en cuanto a intensidad, frecuencia o duración, o bien se activa con estímulos no amenazantes para el organismo, provoca manifestaciones patológicas, tanto a nivel emocional como funcional (Vila, 1984).

Otros términos relacionados son la angustia y el pánico que se suelen asimilar sobre todo cuando se habla de crisis de angustia o ataque de pánico. Resultante de la activación de 
miedo (a veces extremo: a morir, a perder el control o la cordura, desconexión de sí o de la realidad) se acompaña de repercusiones orgánicas llamativas (temblores, ahogo, náuseas, molestias torácicas, palpitaciones y aceleración cardiaca, paralización, sudoración, mareos o desmayo...). En condicione menos críticas o agudas es un sentimiento vinculado a situaciones de desesperación, donde la característica principal es la pérdida de la capacidad de actuar voluntaria y libremente, de dirigir sus propios actos.

La angustia puede ser adaptativa o no, en función de la magnitud con la que se presenta y del tipo de reacciones que se presentan en un momento dado; la proporción, intensidad y duración de las anomalías marca la pauta para su patología. "La angustia normal no implica una reducción de la libertad del ser humano, mientras que la patológica refleja una reacción desproporcionada respecto a la situación que se presenta, siendo más corporal, primaria, profunda y recurrente; este tipo de angustia es estereotipada, anacrónica (revive continuamente el pasado) y fantasmagórica (imagina un conflicto tal vez inexistente)" (Ayuso, 1988, en Sierra, Ortega y Zubeidat, 2003, pág. 28).

\section{2 ... y las relaciones entre ellos}

Ansiedad y miedo son emociones cercanas y tienen expresiones similares en su constelación de elementos. Algunos las consideran diferentes niveles de lo mismo. Se aprecian pensamientos de peligro, sensaciones de aprensión, reacciones fisiológicas y respuestas motoras. También son reacciones funcionales y adaptativas para la supervivencia individual y colectiva. Pero la ansiedad provoca una respuesta más difusa en su objeto, menos orientada, sin identificación clara de la causa, es más una aprensión. Mientras el miedo es una alteración que se manifiesta ante estímulos presentes, la ansiedad se vincula a la anticipación de riesgos futuros, indefinibles e imprevisibles.

De otro modo, el miedo en correlación con la angustia nos enfrenta a una amenaza que no se diferencia mucho en sus elementos fisiológicos y subjetivos. Por un lado, el término miedo se aplica a lo que se entiende como una reacción normal ante un estímulo amenazante o ante una situación de peligro claramente identificable en el ambiente: es reconocible la causa del sentimiento, hay una explicación racional, existe incluso la posibilidad de un fracaso/daño real. En la angustia, por otro lado, se carece de objeto definible y claro, los sentimientos no son tan claramente motivados y existe una respuesta anticipatoria.

De forma parecida se han comentado las confusiones entre conceptos de ansiedad, angustia y estrés. El estrés ha sido abordado desde un modelo integrador bio-psico-social que en su enfoque psicológico concibe el estrés como estímulo, como respuesta y/o como interacción entre ambos. La distinción entre ansiedad y estrés resulta más compleja en la actualidad dado solapamiento entre una y otro; aunque pueden diferenciarse al considerar la importancia de los procesos fisiológicos en el estrés frente a los sentimientos subjetivos implicados en el estado de ansiedad. El estrés se diferencia de la ansiedad y la angustia (v. Sierra, Ortega y Zubeidat, 2003, pág. 50) al considerarse como un resultado del desbordamiento del individuo frente a las demandas del ambiente, mientras en la ansiedad se produce una reacción emocional ante una amenaza que se manifiesta a nivel cognitivo, fisiológico, motor y emocional; la angustia surge cuando se percibe una amenaza a la existencia del individuo, a sus valores morales y a su integridad tanto física como psicológica. 
Una visión gráfica de las emociones del miedo puede representarlas en función de su duración e intensidad (ver Figura 1), y cabría añadir otras dimensiones no representables con facilidad como si se trata de un elemento subjetivo o real, difuso o concreto.

\begin{tabular}{|c|c|c|c|}
\hline \multicolumn{4}{|c|}{ Figura 1. Niveles y términos de las emociones del miedo } \\
\hline \multirow{3}{*}{ قี } & Alta & $\begin{array}{l}\text { Estrés, } \\
\text { ansiedad duradera } \\
\text { o rasgo }\end{array}$ & $\begin{array}{l}\text { Fobia y } \\
\text { trastornos, } \\
\text { indefensión }\end{array}$ \\
\hline & & $\begin{array}{l}\text { Temor, } \\
\text { malestar, } \\
\text { ansiedad controlable }\end{array}$ & $\begin{array}{l}\text { Angustia } \\
\text { Crisis de Pánico }\end{array}$ \\
\hline & \multicolumn{2}{|l|}{ Baja } & Alta \\
\hline \multicolumn{4}{|c|}{ Intensidad } \\
\hline & & Fuente & Jericó (2006) \\
\hline
\end{tabular}

\subsection{La indefensión aprendida y sus consecuencias}

Descubierta por Seligman (inicialmente, en animales), la indefensión aprendida se muestra como incapacidad para reaccionar tras haber sido sometido a castigo o estimulación aversiva, sumiéndose en una actitud de resignación, miedo y ansiedad, aun cuando cambien las condiciones y posibilidades de escapar o evitarlos. En seres humanos se ha reconocido también ese patrón de comportamiento característico de personas sumidas en un estado de impotencia y depresión tras haber estado expuestas a castigos o daños aparentemente aleatorios e inevitables, habiendo tratado de escapar mediante acciones no exitosas. Su permanencia en el tiempo se evidencia como conducta disfuncional que a menudo requiere ayuda profesional y que suele mostrarse como una creencia limitante que lastra el desarrollo personal y la autoestima. La indefensión aprendida suele estar muy presente en personas socializadas en sistemas sociales con un régimen muy autoritario, que se distingue por el castigo y las bajas recompensas. Si en casa o en la escuela o si se ha sido víctima de actos de violencia física o psicológica durante la infancia, es más probable que en la etapa adulta no se defienda ante las dificultades o agresiones y sólo sepa protegerse desde la depresión y la desesperanza (Casado, 2018).

Entre los efectos de la indefensión aprendida se citan los siguientes:

a) A un nivel emocional, el miedo se enquista de forma permanente lo que limita o impide la posibilidad de dar salida a la rabia que favorecería el defenderse.

b) A nivel cognitivo predominan pensamientos de derrota, que le hacen sentirse incapaz de hallar remedios al problema y que a la postre lleva a la resignación de que "debe ser así y no hay nada que hacer".

c) A nivel fisiológico se produce la contradicción entre la activación "simpática" de cara a afrontar el peligro o amenaza de un modo reactivo y adaptativo pero en la medida que no se consigue afrontar la situación para la que se ha activado, se genera una reacción "parasimpática" que permite la desactivación fisiológica, y en lugar de una relajación, 
lo que se da es un bloqueo en la respuesta contraproducente ante una situación hostil o adversa.

d) A nivel conductual y como efecto de los procesos anteriores, hay una dilación en la respuesta voluntaria que va extinguiendo la reacción de huida o lucha. La persona se bloquea y queda congelada sin buscar alternativas de afrontamiento.

Parece que la personalidad y el enfoque más optimista o pesimista pueden influir en la interpretación de las situaciones, en su impacto, efectos y en la responsabilidad que se asume en ellas. Por lo que la forma de recibir o afrontar las situaciones "amenazantes o dolorosas" es relevante para poder interrumpir el ciclo disfuncional que antes se ha descrito.

Como otros comportamientos aprendidos, las reacciones ante el miedo pueden ser modificadas, a través de estrategias alternativas que ayuden progresivamente, a afrontar las dificultades y los conflictos de un modo más adaptativo y favorable ante situaciones aversivas; entre otras cosas asumiendo en lo posible cierto control o capacidad de contener lo que sucede.

\section{El miedo en las organizaciones. Principales efectos}

Las emociones juegan un importante papel en el comportamiento humano y por tanto también lo hacen en el ámbito de las organizaciones y los procesos que en ellas se desarrollan. Dentro del repertorio emocional, aquellas que se relacionan con el miedo (en esa variedad que se ha esbozado antes) han recibido atención en los estudios sobre el comportamiento organizacional y sobre los efectos que tienen en las personas, el desempeño y los resultados organizacionales.

Diferentes perspectivas organizacionales han considerado la dimensión positiva y negativa para los resultados organizacionales que tienen el repertorio de emociones asociadas al miedo (Jericó, 2006; Ryan y Oestreich, 1991; Suárez, 1997; Thongsukmag, 2003). Sin embargo, en la literatura las derivaciones negativas han recibido fundamentalmente más inspección durante los últimos 30 años.

El miedo tiene efectos sobre los trabajadores en su dimensión psicológica y física (priva de autoestima, de la oportunidad de aportar a las metas de la organización, provoca que se callen y no comenten los errores, etc.). Pero también tiene efectos en los resultados organizacionales y sus componentes. En ciertas condiciones el miedo y la hostilidad pueden ser una fuerza negativa dominante dentro de una organización.

Siguiendo trabajos como el de Bedoya y Velásquez (2014) y Bedoya y García-Solarte (2015) que a su vez hacen revisión de la literatura disponible al respecto, se pueden identificar distintas facetas y dimensiones en los que las emociones del miedo se manifiestan en las conductas de personas y organizaciones.

- Alteración del clima y cultura organizacional

- Bajo rendimiento y éxito de la organización

- Deterioro de relaciones laborales

- Disminución o baja productividad

- Enfermedades y trastornos 
- Incapacidad para tomar decisiones

- Pérdida de talento, creatividad e innovación

- Resistencia al cambio

- Silencio de los empleados

Tanto la creatividad como la innovación necesitan de un sentimiento de seguridad que evite el miedo a ensayar o expresar ideas nuevas, que evite el temor al juicio y a ser criticado o hacer el ridículo. Sin esa sensación de aceptación, se inhiben estas propuestas o novedades. Además, la emoción de temor o angustia a un nivel psicobiológico provoca una mayor activación de la fisiología emocional, una focalización preventiva que evita $o$ reduce la capacidad de pensamiento racional, la concentración y la ideación creativa. Trabajos como los de Kriegesmann, Kley y Schwering (2007) ponen el énfasis en la gestión de los riesgos y los errores creativos para evitar el bloqueo de la innovación. Una condena excesiva de los errores, una evaluación negativa, genera miedo a cometerlos y bloquea la innovación y no estimula la creatividad organizacional. Esto se afirma también el estudio de Asad y Al-Dubaisi (2008) sobre las barreras a la creatividad. Para Urda y Loch (2013) las emociones influyen en el comportamiento de diversos modos que son relevantes para el desempeño de los procesos y que esta emoción de miedo inhibe la voluntad de los trabajadores a tomar iniciativas e incita a que eviten riesgos que podrían aportar una mejora continua y favorecer el cambio organizacional.

A un nivel individual, la prolongación en el tiempo de los estados de alerta, estrés y miedo con sus reacciones psicológicas y fisiológicas puede acabar afectando a la salud laboral y calidad de vida de las personas. Como consecuencia puede incitar al consumo, afectar negativamente la salud, suprimir el bienestar psicológico y complicar las relaciones familiares.

En este sentido pueden existir desencadenantes externos objetivos, pero puede permanecer más allá de ellos (Gimpelson y Oshchepkov, 2012). Los momentos de crisis, despidos y regulaciones de empleo, por ejemplo, se han asociado con el incremento en los índices de absentismo por trastornos cardiovasculares e incluso aumento de tasas de mortalidad asociadas. La inestabilidad y el miedo a perder el puesto se han vinculado con este aumento de las enfermedades (v. Vahtera et al. 2004). También pueden darse miedos patológicos con afectación en la salud física, procesos mentales y conductas (en modo de fobias, pánico, trastornos obsesivos...).

A un nivel organizacional, los rendimientos y desempeño se pueden ver alterados por el absentismo, rotación, sustituciones y relevos, retrasos, costes de formación del personal, insatisfacción de clientes o usuarios.

Los efectos negativos sobre el desempeño y la productividad desde el principio estuvieron en el foco de las investigaciones sobre el miedo en las organizaciones. Más allá de los bloqueos individuales en la actividad o acción ligada a su puesto (que se han señalado) pueden, por ejemplo, general la tendencia a ocultar o falsificar datos para ofrecer resultados aceptables o buenos y evitar sanciones o ser represaliados. Esto origina efectos adversos en la organización ya que se pierde una visión objetiva y real del funcionamiento interno.

Una consecuencia de esos procesos reactivos al miedo puede afectar a la toma de decisiones, que se encuentra comprometida por el manejo de información y conocimientos 
adecuados a la situación. La ambigüedad e incertidumbre suele atenazar las decisiones de ciertas personas con mayor responsabilidad como gerentes y directivos, que se ven obligados a afrontar las ambigüedades, fluctuaciones y dilemas que están fuera de su zona de confort o seguridad. Un ejemplo puede verse en el trabajo de Guénin-Paracini, Malsch y Marché (2014) sobre los auditores, quienes pueden obviar datos o evitar procesos confrontativos y que podría acabar ofreciendo una visión incompleta o distorsionada; otra muestra en el de Coget, Haag y Gibson (2011) sobre directores de cine a la hora de tomar decisiones irracionales y parciales.

No aislado de lo anterior, está claro que las emociones del miedo están ligadas y dependen del comportamiento de directivos y de la eficacia de su gestión. También los supervisores tienen efecto en la génesis de emociones positivas, frente a las negativas, para vincularlas con mejores desempeños y resultados. La presencia de diversas emociones negativas y entre ellas el miedo, puede limitar la influencia social de los líderes formales y reducir la disposición a cumplir con lo no esencial, tendencia a maximizar el descanso o permisos, y otras conductas. Por otro, lado el recurso al miedo ha sido nuclear en los estilos coercitivos de control y dirección. La posibilidad de castigo produce reacciones que no lleva a efectos deseados como la ansiedad, la reducción del esfuerzo, la desconfianza y la depresión, desde luego siendo abono a un clima no cooperativo y atemorizado (v. ZoghbiManrique, 2006).

Como se ha dicho los empleados pueden optar por callar y mantener el silencio, evitando consecuencias negativas que tanto para su situación laboral como su promoción profesional puede tener el comentar asuntos delicados. Distintos autores (Fapohunda, 2016; Milliken y Morrison, 2003; Milliken, et al., 2003; Ryan y Oestreich, 1991) relacionan el tema del miedo en el lugar de trabajo con el sentimiento a posibles consecuencias como resultado de hablar o de contar preocupaciones y errores asociados a los fenómenos organizacionales. Se prefiere no señalar problemas, evitando así ser señalados o culpados por ellos, que sus supervisores perciban amenazas o reaccionen con deseos de represalia. Eluden también el asilamiento o la exclusión grupal, ser juzgados como empleados polémicos o reclamantes, dañar las relaciones, perder aceptación o apoyo. Callar para mantener el estatus, perder oportunidades promocionales o entrar en controversias. Además, es una reacción amplia en la plantilla. Muy pocos se sienten cómodos compartiendo los problemas o lo hacen restringiendo los aspectos y personas con quienes los comentan. Se habla más del trabajo que de los problemas de la organización. Pocos confían en que sirva para algo o que sean escuchados.

Pohler y Luchak (2014) ya pusieron de manifiesto la importancia de sistemas organizacionales y de gestión de recursos humanos que permitan y activen la voz de los empleados en combinación con los sindicatos. Morrison, See, y Pan (2015) en tres estudios comprobaron como el sentimiento de impotencia o indefensión, carecer de poder, correlacionaba y explicaba el silencio de los empleados, pero a la vez, que la expresa apertura y disponibilidad de los managers lo contrarrestaba y evitaba. Algo que Donaghey et al. (2011) ya habían planteado al considerar que las prácticas directivas organizacionales eran responsables del mantenimiento estructural y de la perpetuación del silencio.

Esto lleva a pensar que el clima de relaciones laborales y la cultura organizacional se ven implicados cuando las emociones del miedo cunden entre los empleados, abunda la desconfianza y se percibe un ambiente de amenaza continua. Es lógico pensar que la moral 
de los empleados está dañada. El clima organizacional resulta amenazante, la comunicación no fluye con soltura, puede haber divisiones departamentales o suspicacias, falla la cooperación, la participación no es adecuada o es baja y se rehúyen las novedades, innovaciones o contribuir a las necesidades de calidad o cambio. Esto afecta tanto al potencial de los empleados como a la efectividad organizacional. Pueden darse respuestas de sumisión, no se toman riesgos, las decisiones se toman basadas en procesos intuitivos o con foco en información personal. También se ha encontrado una mayor tendencia a no asumir responsabilidades, un aumento de las excusas, la justificación o la negación (v. Hareli, Shomrat y Biger, 2005). La cultura del miedo si enraíza en la visión de la organización limita el conocimiento organizacional compartido, ya que el dominio de este se considera una fuente de poder en un entorno peligroso.

Por supuesto, la resistencia al cambio es el otro corolario de este clima y cultura organizacionales. En la medida que el cambio puede amenazar las pocas seguridades o las estrategias de afrontamiento ante riesgos y emociones de miedo, las tradiciones y costumbres que dan seguridad y las prácticas consolidadas se convierten en anclajes ante la incertidumbre de escenarios nuevos o sobre los que hay poca información. De ahí que una mayor y sistemática comunicación y participación sobre cambios sobrevenidos o por asumir, contrarresta la inseguridad y amortigua el miedo y sus respuestas negativas.

Todos los inconvenientes apuntados se viven con su especificidad de complejidad y efectos en los distintos niveles individuales, grupales y organizacionales, adoptando matices en cada uno. Martínez-Jurado (2017) hace énfasis en elementos llamativos y comunes:

- La psicología del temor convierte la esencia de las organizaciones en reactiva, en lugar de proactiva.

- El modo supervivencia se convierte en el común denominador de cualquier actividad profesional, desembocando en un espíritu falto de autocrítica y de asunción de responsabilidades.

- El continuo afectivo que se genera va desde la hostilidad encubierta hasta la animadversión más profunda y abiertamente declarada.

- El círculo vicioso de la ansiedad y el estrés sostenido hunde sus raíces en la indefensión aprendida, pudiendo llegar a hacer mella en el equilibrio mental y la salud física de los profesionales.

- También afecta a las creencias y los valores tanto individuales como colectivos. La esperanza queda así arrinconada en el mostrador de objetos perdidos, mientras el talento migra y se oscurece cualquier atisbo de proyección hacia el futuro.

\section{Miedo en la Universidad como organización}

\subsection{Tipos de miedo, necesidades y actores de la comunidad}

Resulta evidente que las universidades son organizaciones formales que plasman en concreción la institución de la educación superior. Por tanto, muchas de las apreciaciones que se han comentado sobre el efecto de las emociones del miedo en el funcionamiento organizativo e institucional son totalmente aplicables. Más aún cuando las universidades se 
ubican en un entorno donde existe una tensión constante entre hábitos y tradiciones centenarias y exigencias y retos de una sociedad marcada por la globalización, la cibernética y diversos problemas sociales, económicos y culturales.

Autores y divulgadoras como Jericó $(2006,2010)$, plantean el choque del paradigma del miedo en la gestión y el sistema "No-Miedo" basado en el talento, el cambio y la innovación. En el contraste entre ellos se destaca un contexto en el que la competencia existente en el sistema económico es imprevisible y los mercados inestables, los clientes (usuarios) son libres de elegir, se va a requerir innovación y creatividad, y el desarrollo del potencial de los profesionales que además deben ser creadores. Por tanto, ya no sirve un enfoque de previsibilidad, repetición de tareas, obediencia y automatismos, clientes cautivos y un miedo toxico. No es que el miedo o cautela ante los riesgos deba ser obviado o eliminado, ya que tiene un componente adaptativo y funcional, sino que lo que se rechaza es el miedo "tóxico", paralizante y contrario a la innovación, al talento, la creatividad y la asimilación de los cambios.

De ahí que su propuesta se base en desmenuzar los tipos de miedo más comunes en las organizaciones en las que se da una gestión que se apoya en esa familia de emociones. Por otro lado, se oponen novedades en los mecanismos de actuación-gestión entre los que menciona el proyecto de empresa (organización), el poder y la autoridad, el sistema de gestión de recursos humanos, la comunicación y el liderazgo. Si hacemos una adaptación y ampliación de su proposición al contexto universitario se podría visualizar como en la Tabla 1.

\begin{tabular}{|c|c|c|}
\hline Necesidad o motivación & Miedo a... & Miedo extendido a... \\
\hline $\begin{array}{l}\text { Básicas-supervivencia } \\
\text { (bienestar y cobertura } \\
\text { de estándar mínimo de } \\
\text { vida) }\end{array}$ & $\begin{array}{l}\text { No supervivencia, } \\
\text { carencias básicas, } \\
\text { sanciones o daños }\end{array}$ & $\begin{array}{l}\text { Perder trabajo, no conseguir empleo o medio de } \\
\text { subsistencia (empleabilidad), pobreza, precarie- } \\
\text { dad, pérdida económica o de oportunidades (v.g. } \\
\text { perder una beca...). } \\
\text { Agresión física, conducta amenazante, abuso } \\
\text { verbal }\end{array}$ \\
\hline Afiliación y vinculación & $\begin{array}{l}\text { Rechazo y } \\
\text { exclusión } \\
\text { Vergüenza y } \\
\text { separación }\end{array}$ & $\begin{array}{l}\text { Expulsión del grupo, rechazo y aislamiento, no } \\
\text { ser atendido o ser postergado, discriminación, } \\
\text { desafecto, relaciones toxicas }\end{array}$ \\
\hline Logro, éxito, promoción & $\begin{array}{l}\text { Fracaso, } \\
\text { estancamiento, } \\
\text { sanciones }\end{array}$ & $\begin{array}{l}\text { No titularse, no estabilizarse, promocionar, o } \\
\text { ser reconocido. Miedo al error, riesgos y toma } \\
\text { de decisiones. Ausencia de feedback positivo por } \\
\text { esfuerzo y rendimiento. }\end{array}$ \\
\hline $\begin{array}{l}\text { Poder, influencia } \\
\text { (estatus) }\end{array}$ & $\begin{array}{l}\text { Debilitamiento, } \\
\text { impotencia }\end{array}$ & $\begin{array}{l}\text { Perder autoridad, liderazgo o influencia, no ser } \\
\text { elegido, perder un puesto jerárquico }\end{array}$ \\
\hline $\begin{array}{l}\text { Conjunto Estabilidad- } \\
\text { Seguridad }\end{array}$ & $\begin{array}{l}\text { Al cambio y } \\
\text { perdida de } \\
\text { seguridad en logro } \\
\text { de necesidades }\end{array}$ & $\begin{array}{l}\text { Perdida/alteración de roles o puestos deseados, } \\
\text { alteración de condiciones de trabajo o laborales. } \\
\text { Movilidad forzosa. Desestructuración o deterioro } \\
\text { de reglas legales y atribuciones. }\end{array}$ \\
\hline
\end{tabular}


Tabla 2. Miedos comunes en estamentos y personas de la comunidad universitaria

\begin{tabular}{|c|c|}
\hline $\begin{array}{l}\text { Personas, grupo } \\
\text { o estamento }\end{array}$ & Miedos comunes \\
\hline Estudiantes & $\begin{array}{l}\text { Suspender, repetir, fracasar } \\
\text { Gastos por pérdida de becas o por recargos } \\
\text { Rechazo, exclusión por compañeros } \\
\text { Enfrentamientos o represalias de docentes (v.g. reclamar examen o presentar queja / po- } \\
\quad \text { sibles represalias en otras asignaturas/ evaluaciones posteriores; aceptar abusos como } \\
\quad \text { tener que comprar su libro); o de compañeros (aceptar novatadas...) } \\
\text { Discriminación, no igualdad de oportunidades } \\
\text { Formación inadecuada y perdida de empleabilidad }\end{array}$ \\
\hline
\end{tabular}

Inestabilidad laboral, pérdida de empleo o puesto

Restricción o perdidas oportunidades de promoción

Cambios en condiciones de trabajo o laborales.

Personal de Administración Dificultades para cubrir horarios, exigencias tecnológicas y conciliación.

y Servicios (PAS) Innovaciones organizativas, procedimentales o técnicas poco soportadas o impuestas que alteran desempeño y valoración laboral

Enfrentamientos con usuarios (docentes, estudiantes, otros compañeros).

Acoso moral o sexual. Aislamiento

Represalias por supervisores o cargos

Conflictos y dilemas éticos

\begin{tabular}{|c|c|}
\hline $\begin{array}{l}\text { Personal } \\
\text { Docente e } \\
\text { Investigador } \\
\text { (PDI) }\end{array}$ & $\begin{array}{l}\text { Inestabilidad laboral, } \\
\text { Bloqueo en carrera profesional, estancamiento } \\
\text { Requerimientos y exigencias crecientes } \\
\text { Impacto en conciliación familiar y vida personal } \\
\text { Pérdida de oportunidades de investigación y visibilidad o desarrollo profesional e intelectual } \\
\text { Enfrentamientos con otros usuarios (estudiantes, colegas, PAS o supervisores). } \\
\text { Acoso moral o sexual } \\
\text { Aislamiento } \\
\text { Malas evaluaciones de su docencia (por estudiantes o centros) } \\
\text { Conflictos y dilemas éticos o deontológicos. } \\
\text { Pérdida de identidad o autoridad como docentes o investigadores } \\
\text { Represalias por supervisores o cargos }\end{array}$ \\
\hline $\begin{array}{l}\text { Representantes } \\
\text { estudiantiles y } \\
\text { sindicales }\end{array}$ & $\begin{array}{l}\text { Pérdida de representatividad y seguidores } \\
\text { Pérdida de visibilidad } \\
\text { Pérdida de poder de negociación e influencia en toma de decisiones. } \\
\text { Luchas o desgaste entre grupos o rivales. } \\
\text { Rupturas y discrepancias internas } \\
\text { Represalias por supervisores o cargos }\end{array}$ \\
\hline $\begin{array}{l}\text { Responsables } \\
\text { de equipos de } \\
\text { investigación } \\
\text { o de centros y } \\
\text { facultades }\end{array}$ & $\begin{array}{l}\text { Pérdida de apoyos, seguidores } \\
\text { Pérdida de poder de negociación e influencia en toma de decisiones } \\
\text { Limitaciones en acceso a recursos, prerrogativas y/o privilegios } \\
\text { Toma de decisiones controvertidas o impopulares que menoscaben su apoyo "político" }\end{array}$ \\
\hline $\begin{array}{l}\text { Autoridades y } \\
\text { gestores }\end{array}$ & $\begin{array}{l}\text { Que los recursos no alcancen a los fines u objetivos de su planteamiento político } \\
\text { Toma de decisiones controvertidas o impopulares que menoscaben su apoyo "político" } \\
\text { Conflictos y dilemas éticos } \\
\text { Contestación o crítica por los gobernados } \\
\text { Cambios e imprevistos negativos en el entorno organizacional (socioeconómico, político y legal) } \\
\text { Escándalos y exposición negativa en la opinión pública (intra y extra organizacional) } \\
\text { Rupturas y discrepancias internas en soportes o elementos claves. Deslealtad o traición. }\end{array}$ \\
\hline
\end{tabular}


Claramente, estas motivaciones y miedos se extienden entre las personas y estamentos de la comunidad universitaria, en su contexto concreto, funciones y roles que ocupan. Así, en un estudiante el miedo a perder una beca, a tener que afrontar gastos por repetición de asignaturas o incluso ver sancionada su permanencia por no superar un mínimo de créditos, afectaría a sus necesidades básicas y desarrollo personal (profesional). Ver alterados por una ley o recorte presupuestario las condiciones retributivas o condiciones laborales, e incluso el sostenimiento de puestos en el personal laboral o contratado a tiempo parcial, afectaría a necesidades básicas y al conjunto de la estabilidad-seguridad. Un endurecimiento imprevisto o no justificado de las exigencias o sistemas de acreditación, perturbaría el logro, estabilidad y promoción del PDI. Un o una representante estudiantil, un investigador principal (IP) en un grupo, una decana, que no fuesen aceptados, apoyados, sostenidos en sus funciones o puestos, verían comprometidos su afiliación y vinculación con representados o colegas y, además, esto podría tener consecuencias evidentes en su capacidad de influencia y liderazgo. También puede sentir miedo una persona con orientación de género no convencional, grupo étnico minoritario, creencias religiosas no comunes, morfología corporal, o algún hándicap, etc., a ser percibido como diferente y recibir el rechazo, la no aceptación.

La Tabla 2 resume, sin agotarlas, las posibles manifestaciones de emociones de temor o miedo en diferentes personas de la comunidad universitaria, tal y como a veces son recogidas o recibidas explícita o sobre-entendidamente en las Defensorías Universitarias (DUs) y en la participación institucional.

\subsection{Comportamientos no éticos o disfuncionales, factores de amenaza}

Por otro lado, la problemática de culturas o ambientes de miedo (más o menos extendidos) $\mathrm{o}$, al menos a menor escala, procesos y fenómenos organizacionales y profesionales que se ven invadidos o contaminados por esas emociones; no son independientes de conductas disfuncionales o negativas en ese mismo contexto.

Más allá de que existan factores incontrolables en el ambiente y devenir de las organizaciones actuales (esto es, variables amenazadoras efectivas o no e imprevisibles a veces), también a menudo las reacciones ligadas al miedo son producto, o se ven acentuadas, por procesos negativos o comportamientos no éticos en personas e instancias organizacionales.

Trabajos como los de Andreoli y Lefkowitz (2009) y Lefkowitz (2009), sintetizaban los elementos conceptuales interrelacionados en las malas conductas en las organizaciones (v. Tabla 3).

No es difícil identificar factores que resultan amenazantes tanto para las personas como para la organización por el hecho de que suponen una clara violación de los estándares de confianza y seguridad en las relaciones interpersonales o en las garantías de trato adecuado y justo por parte de la organización y sus actores principales (sean colegas, subordinados o supervisores y responsables).

Luego, las infracciones concretas que alteran el clima y la convivencia, que amenazan la satisfacción de necesidades primarias, o dificultan el mantenimiento de necesidades o 
Tabla 3. Constructos superpuestos que describen la falta de ética en las organizaciones

\begin{tabular}{|c|c|c|c|}
\hline Constructo & Criterio de definición & Supuestos motivacionales & Objetivos y resultados \\
\hline $\begin{array}{l}\text { Comporta- } \\
\text { miento no ético }\end{array}$ & $\begin{array}{l}\text { Violación de princi- } \\
\text { pios morales }\end{array}$ & $\begin{array}{l}\text { Fallo inintencionado al } \\
\text { ajustarse a los propios es- } \\
\text { tándares; o abuso de con- } \\
\text { fianza interesado e inten- } \\
\text { cional }\end{array}$ & $\begin{array}{l}\text { Daño o infracciones ha- } \\
\text { cia los demás }\end{array}$ \\
\hline $\begin{array}{l}\text { Comporta- } \\
\text { miento descor- } \\
\text { tés o maledu- } \\
\text { cado }\end{array}$ & $\begin{array}{l}\text { Violación de normas } \\
\text { y convenciones so- } \\
\text { ciales }\end{array}$ & Acciones intencionales o no & $\begin{array}{l}\text { Daño menor, falta de } \\
\text { respeto o insulto a los } \\
\text { demás }\end{array}$ \\
\hline $\begin{array}{l}\text { Desviación } \\
\text { organizacional }\end{array}$ & $\begin{array}{l}\text { Violación de normas } \\
\text { organizacionales }\end{array}$ & $\begin{array}{l}\text { Hechos intencionales, no } \\
\text { intencionales o accidentales }\end{array}$ & $\begin{array}{l}\text { Daño a los otros o a la } \\
\text { organización }\end{array}$ \\
\hline $\begin{array}{l}\text { Corrupción } \\
\text { organizacional }\end{array}$ & $\begin{array}{l}\text { Violación de normas } \\
\text { públicas de con- } \\
\text { fianza }\end{array}$ & $\begin{array}{l}\text { Abuso de confianza inten- } \\
\text { cional para beneficio perso- } \\
\text { nal o colectivo }\end{array}$ & $\begin{array}{l}\text { Daño a otros o a la orga- } \\
\text { nización }\end{array}$ \\
\hline $\begin{array}{l}\text { Mal comporta- } \\
\text { miento organi- } \\
\text { zacional }\end{array}$ & $\begin{array}{l}\text { Violación de normas } \\
\text { organizacionales } \\
\text { (y/o públicas) }\end{array}$ & $\begin{array}{l}\text { Transgresiones intenciona- } \\
\text { les en nombre propio o de la } \\
\text { organización }\end{array}$ & $\begin{array}{l}\text { Daño menor o consi- } \\
\text { derable; o beneficio de } \\
\text { otros, o de la organiza- } \\
\text { ción, dependiendo de las } \\
\text { normas quebrantadas }\end{array}$ \\
\hline $\begin{array}{l}\text { Conducta labo- } \\
\text { ral contrapro- } \\
\text { ducente }\end{array}$ & $\begin{array}{l}\text { Violación de normas } \\
\text { organizacionales y } \\
\text { públicas }\end{array}$ & $\begin{array}{l}\text { Acciones intencionales in- } \\
\text { teresadas (egoístas) }\end{array}$ & $\begin{array}{l}\text { Daño menor o conside- } \\
\text { rable a otros o a la orga- } \\
\text { nización }\end{array}$ \\
\hline
\end{tabular}

Fuente: traducido de Lefkowitz, 2009.

aspiraciones adquiridas en el desarrollo personal o devenir profesional, correlacionan en gran medida con el miedo percibido, subjetivo y real en su apreciación, por aquellos actores en el sistema que se sienten más débiles o con menos poder para controlar o afrontar las contingencias. Es, precisamente, la constatación de la desigualdad, de la diferencia de oportunidades, del acceso no semejante a la información, de la inequidad.

Excedería del espacio de este trabajo hacer una explicación exhaustiva de las conductas inadecuadas, infracciones o cuestiones más graves desde el punto de vista ético, deontológico o legal/penal, que se detectan en las universidades tal como en otras organizaciones y comunidades. Desde cuestiones que implican violencia real o simbólica, directa, verbal y psicológica como las amenazas y agresiones (v. Cornell, 2010; Lindo, Siminski, y Swensen, 2018), el acoso moral (v. Einarsen y Hauge, 2006; Leymann, 1990; Quiros-Garcia, 2019), el acoso sexual (v. Rudman, Borgida, y Robertson, 1995), cyberbulling (v. Mateus et al. 2014); pasando por otras como la corrupción, nepotismo o favoritismo, malversación de fondos, prevaricación, absentismo fraudulento, discriminación por diferentes causas; a otras más específicas del ámbito académico como la suplantación de identidad, fraude en exámenes, novatadas, plagio, falsificación o "cocinado" de datos de investigación... 
Además de la atención recibida en la investigación científica organizacional, victimiológica y jurídica, es muy frecuente la aparición de escándalos y visibilidad mediática, de modo que afloran casos concretos o interpelaciones a la opinión pública general, hablando especialmente de violaciones y acoso sexual (entre docentes y estudiantes), la "ley del silencio", denuncias por discriminación machista o corrupción en procesos, plagios, etc. (v. ATU Spain, https://atuspain.es; Borraz, 2017; Jara, 2018; Polo, 2015;Villasante, 2017).

Obviamente, en los roles y competencias que tienen atribuidas las DUs se intercalan con probabilidad las diferentes problemáticas que se vienen comentando en los enunciados anteriores. Contribuir a garantizar los derechos y libertades de la ciudadanía universitaria, y apoyar y aportar en la mejora de la calidad del funcionamiento y realización de fines de la institución universitaria, supone a menudo vérselas con estos temores y con la necesidad de recordar deberes y responsabilidades a los actores que conviven en la universidad (sea cual sea su nivel o función) y a confrontar los comportamientos disfuncionales o inadecuados.

\subsection{Las Defensorías Universitarias y el miedo a quejarse o denunciar}

Aunque no exclusivamente, ya que comparte con la Inspección de Servicios y otras instancias de autoridad académica, las Defensorías Universitarias son lugar habitual para la recepción de quejas sobre problemas o mal funcionamiento que afectan a derechos o atribuciones. A menudo son desajustes funcionales, interpretaciones normativas, controversias de opinión o de actuación, que no suelen tener mala fe o conciencia de que se puede estar trasgrediendo un principio de convivencia o un procedimiento regulado legal o técnicamente en la organización universitaria. Por desgracia, en otros casos se está más cerca de la omisión, dejación de funciones, la percepción e interpretación sesgada y egoísta o la actuación interesada en pro de algún tipo de rendimiento/recompensa particular que puede adoptar diversas formas para la persona o grupo de pertenencia.

En todo caso, se trate de un desajuste, de un conflicto, de una discrepancia o crítica, de un comportamiento no competente o ajustado a los requerimientos básicos y razonables, o bien sea cuestión más severa o más cuestionable desde el punto de vista legal o ético; lo que suele ser habitual es el temor a las consecuencias y efectos de su queja o denuncia por parte de las personas que la presentan (por ser afectadas directamente o por ser testigos del mal funcionamiento y sentirse impelidas moralmente u organizacionalmente a señalarlas).

Es cierto que las Universidades están avanzando mucho con afán preventivo en algunos elementos que a la vez que pueden abordar problemas o disfunciones en procedimientos normalizados y de uso corriente, sirven, a su vez, de instancias organizativas ante las que presentar todo tipo de quejas, señalamiento de hechos o conductas cuestionables y denuncias. Un ejemplo de modelo preventivo sería el presentado por Weisenbach, Hughes y Hertz (2011) para prevenir y mitigar amenazas y riesgos en los campus (ver Figura 2). Ejemplos de productos o elementos preventivos serían resumidamente:

- Códigos éticos y modelos de buenas prácticas. En este caso se establecen principios orientadores y reguladores de los comportamientos y actitudes que son deseables y valorados. Establece reglas, recomendaciones y se asumen compromisos de un modo general o por sistemas o ámbitos más específicos (investigación, publicación, igualdad, docencia, aprendizaje...véase, por ejemplo, Boix-Palop. 2018). 
Figura 2. Modelo para valoración de amenazas

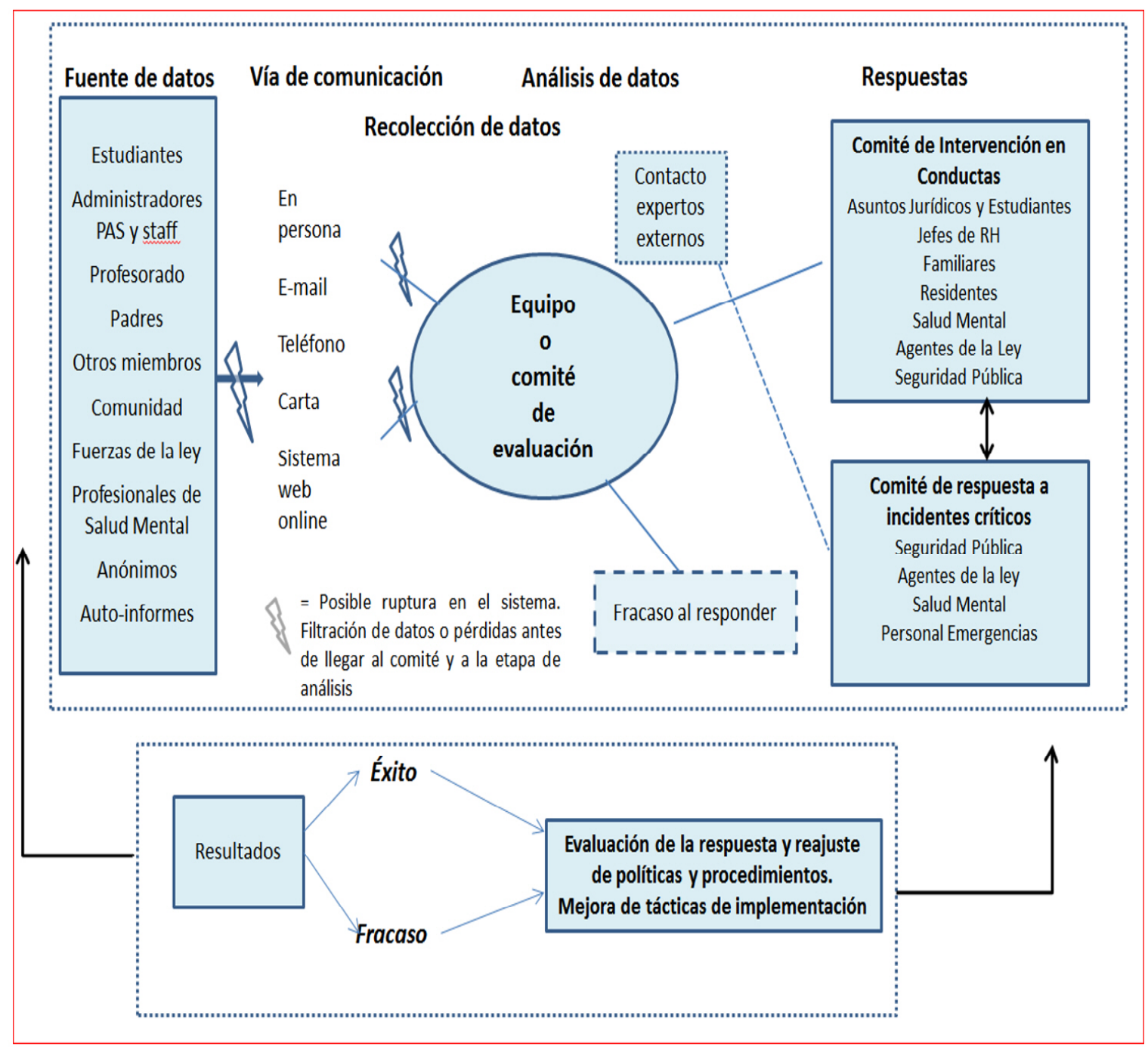

Fuente: traducido de Weisenbach et al. (2011).

- También se pueden relacionar aquí los Protocolos de prevención de malas prácticas o resolución de conflictos (acoso laboral o por razón de sexo, género u orientación). Suelen ir acompañados con comités de regulación, seguimiento y aplicación.

- Responsabilidad Social Corporativa y Transparencia. Muy cercana o vinculada con los anteriores se abre a diversas dimensiones y aspectos sensibles del funcionamiento organizacional como una preocupación por dar cuenta, detectar y apoyar necesidades y re-acciones de la organización universitaria sobre esos temas.

- Sistemas de Aseguramiento Interno de Calidad (SAIC). Aunque están orientados más a alcanzar estándares de calidad en el logro de resultados y cumplimiento de objetivos para reforzar el reconocimiento y acreditación de títulos y centros, a menudo permiten y recogen quejas, insatisfacciones o problemas percibidos o experimentados por los participantes. 
- Buzones de Quejas y Sugerencias (y Felicitaciones). De carácter general o más acotados a centros o servicios, recogen este tipo de aportaciones y pueden hacerlo de un modo identificado (especialmente si se desea respuesta) o anónimamente.

Partiendo de esa realidad, se pueden realizar ciertas observaciones o afirmaciones:

- Las Defensorías Universitarias encuentran en los citados "códigos o modelos" elementos normativos adicionales y complementarios en los que apoyarse, o con los que interactuar, para realizar su función "defensora" y para interpretar situaciones y demandas presentadas.

- Es común observar que muchas de las consultas y quejas (sobre asuntos ordinarios) que se presentan o presentaban en las DUs, son o pueden ser canalizadas por otros sistemas.

- A menudo, las demandas ante la ombudsperson (defensor o defensora) puede ser resultado de un desconocimiento de los canales ordinarios de los títulos o centros, y precisamente se busca que la DU informe u oriente sobre cómo proceder.

- Pero en otros casos, existe una complejidad añadida que tiene que ver con cuestiones de comportamiento organizacional, situados entre la norma o regulación del procedimiento y los aspectos subjetivos y de temor, e incluso, comportamientos que se acercan a lo ilícito. Por ejemplo: a) la queja o denuncia tiene que ver con personas de las que dependen evaluaciones de rendimiento, tienen autoridad o poder para represaliar; b) se busca confidencialidad y protección para la queja o alerta que se comunica; c) no hay confianza en los canales ordinarios por frustración o impotencia ante otras situaciones antecedentes; d) se busca una respuesta de mayor nivel; e) se temen reacciones corporativistas o tergiversadas que acaben dañando al demandante; f) se siente falta de apoyo de compañeros o supervisores, y se encuentran solos o aislados en la queja; $g$ ) en general, cuestiones en las que hay temor o no se tienen todos los elementos de prueba, influencia, o control de contingencias, donde se busca un apoyo o interposición neutral, un arbitraje o intermediación, y no se tiene la seguridad o recursos personales o no se desea actuar litigiosamente. En todas estas ocasiones, la persona que hace la consulta, queja o demanda, pide mucha cautela con su caso, se acoge a la confidencialidad y guarda del anonimato que puede ofrecerle la actuación del defensor o defensora.

\subsection{El temor a quejarse o denunciar y el miedo a las represalias}

La cuestión de las quejas o denuncias aumenta su potencial de convertirse en una situación complicada, amenazante y hasta dramática, para las personas de la comunidad universitaria que las presentan. Habitualmente en función de variables como: la gravedad del asunto, la dependencia del criterio/decisiones de las personas o grupos que son señalados y especialmente la percepción o experiencia de represalias por presentarlas. 
Figura 3. Modelo cognitivo-emocional de represalias a denunciantes

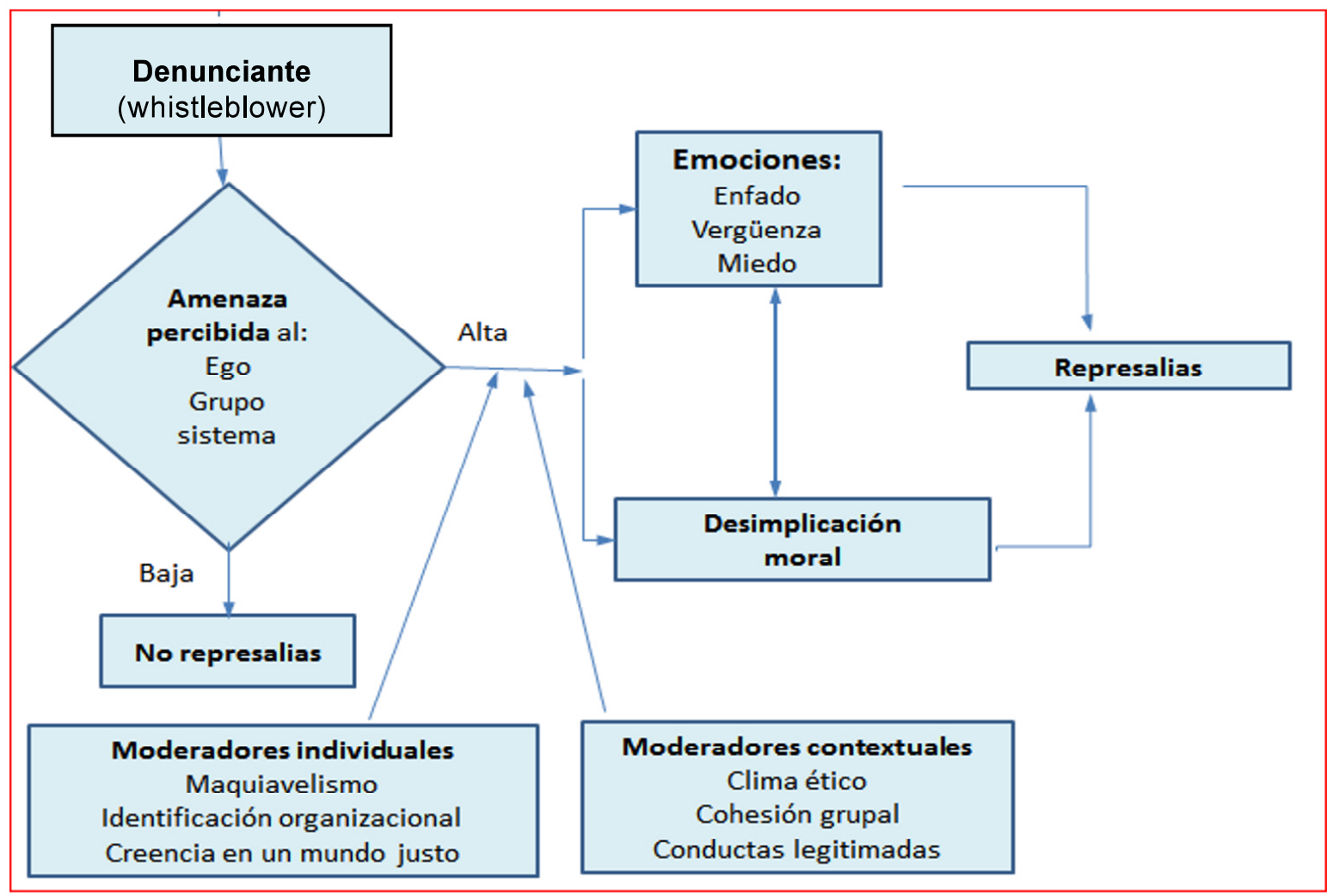

Fuente: Sumanth, Mayer\& Kay, 2011.

La conducta de denuncia o alertamiento de acciones indebidas o malas conductas (whistleblowing) ha ganado mucha atención en los estudios organizacionales (v. Kenny, Fotaki, y Vandekerckhove, 2020; Mesmer-Magnus y Viswesvaran, 2005; Sincoff, Slonaker y Wendt, 2006; Sumanth, Mayer\& Kay, 2011). La investigación y consideración de este fenómeno a menudo se vincula y asocia con el temor o realidad de represalias (retaliation) contra los denunciantes, alertadores o informadores (whistleblowers). La Figura 3 muestra un modelo propuesto para entender precisamente las variables cognitivas y emocionales que activan la conducta de represalia contra los informantes, así como otras que pueden moderarla o incrementarla.

Grandes organismos como la Pan-American Health Organization (2009), la Organización para la Cooperación y el Desarrollo Económicos (OECD, 2016), la Comisión Europea (European Commision, 2018) plantean informes o recomendaciones explícitas para atender las denuncias y proteger contra las represalias (por ejemplo, ver Tabla 4). A finales de 2019 el Consejo y el Parlamento Europeo emiten la Directiva 2019/1937 relativa a la protección de las personas que informen sobre infracciones del Derecho de la Unión, la cual instaura un marco normativo común para las legislaciones de los países miembros que habrán de acogerse y hacer transposición a sus propios regímenes legislativos. Asimismo, establece finales de 2025 para considerar las estadísticas y el impacto de la directiva y, en su caso, actualización, mejora o ampliación.

Esto supone una muy clara apuesta de varios organismos internacionales por regular y orientar la respuesta a esta problemática en el mundo de las empresas y los puestos de 
Tabla 4. Protección anti-represalias

\section{Protección contra las represalias}

17. Como la gente que trabaja en la OPS tiene el derecho y la obligación de denunciar actos presuntamente indebidos y cooperar con las investigaciones o las auditorías, la organización a su vez tiene la obligación de proteger a esas personas de cualquier tipo de represalia en el lugar de trabajo mientras se sustancie una investigación o una auditoría o después de que hayan finalizado.

18. En virtud de esta política, los contratistas, proveedores y asociados que denuncien de buena fe presuntos actos indebidos en los que estén implicados personas que trabajan en la OPS o quienes cooperen en una investigación o auditoría también estarán protegidos, en la medida de lo posible, de las represalias.

19. Una persona que de buena fe denuncie o aporte información estará protegida de las represalias si tiene motivos razonables para creer que la información es cierta y que se han producido actos indebidos o reñidos con la ética o es probable que se produzcan.

20. Una persona que presente una denuncia de buena fe estará protegida de las represalias por más que, luego, la alegación resulte infundada o no sustentada en datos probatorios.

21. Si se estableciera que una denuncia es intencionalmente falsa o engañosa o ha sido formulada dolosamente o de mala fe, cabe adoptar medidas disciplinarias contra la persona que la haya presentado.

22. Es más, una persona que aporta información puede ser objeto de medidas disciplinarias si se determina que ha incurrido en actividades indebidas o faltas de conducta.

Fuente: PAHO, 2009.

trabajo y que por extensión y con sus peculiaridades afectan también a las universidades como organizaciones complejas y servicio público que son.

Es común por ello que, en numerosas instituciones universitarias en el contexto americano tanto al norte como en Latinoamérica, existan protocolos y documentos que explicitan políticas anti-represalias (anti-retaliation policy), y que estos aparezcan como aspectos normativos, estatutarios o como especificaciones en el ámbito de gestión de recursos humanos orientados a combatir las malas conductas, la discriminación y el acoso. Como ejemplo, puede verse un fragmento introductorio de la Universidad para la Paz en Costa Rica y, adicionalmente, enlaces a otros protocolos en diversas universidades (véase Tabla 5 y Tabla 6). 
Tabla 5. Política de protección contra represalias. Introducción general en la Universidad para la Paz (2017)

\section{Sección 1: General}

1.1 Es deber de los miembros del personal, estudiantes, académicos visitantes, profesores visitantes, pasantes y otras personas a quienes se aplican las políticas de la Universidad informar cualquier incumplimiento material de las normas, reglas, procedimientos administrativos o políticas de la Universidad a uno o más funcionarios cuya responsabilidad es tomar las medidas apropiadas. Una persona que hace tal informe tiene derecho a ser protegida contra represalias. Se presume que un individuo hace tal informe de buena fe a menos y hasta que se demuestre lo contrario.

1.2 También es deber de los miembros del personal, estudiantes, académicos visitantes, profesores visitantes, pasantes y otras personas a quienes se aplica esta política cooperar con las auditorías e investigaciones debidamente autorizadas. Una persona que coopera con una auditoría o investigación debidamente autorizada tiene derecho a estar protegida contra represalias. Se presume que un individuo coopera de buena fe a menos y hasta que se demuestre lo contrario.

1.3 Las represalias contra personas que han denunciado conductas indebidas o que han cooperado con auditorías o investigaciones violan la obligación fundamental de todos los miembros del personal, estudiantes, académicos visitantes, profesores visitantes, pasantes y otras personas a quienes se aplican las políticas de la Universidad, de mantener los más altos estándares de eficiencia, competencia e integridad y para cumplir con sus funciones y regular su conducta teniendo en cuenta los mejores intereses de la Universidad.

1.4 Represalia significa cualquier acción perjudicial directa o indirecta recomendada, amenazada o tomada por un individuo involucrado en una conducta protegida por la presente política. Cuando se establece, la represalia es en sí misma una mala conducta y, aunque no necesariamente, también puede constituir una conducta prohibida en el sentido de la Política de la UPAZ sobre Prohibición de la discriminación, el acoso, incluido el acoso sexual y el abuso de autoridad.

Tabla 6. Enlaces a ejemplos de protocolos anti-represalias en universidades americanas

The University of Pennsylvania https://www.hr.upenn.edu/policies-and-procedures/poli-

cy-manual/other-policies/policy-against-retaliation

Fordham University (N.Y.) https://www.fordham.edu/info/25420/university_whistleblower_ policy

Harvard University https://hr.harvard.edu/staff-personnel-manual/general-employment-policies/non-retaliation

The University of Texas at Austin https://policies.utexas.edu/policies/protection-retaliation-suspected-misconduct-reporting-whistleblower

University of Central Florida https://compliance.ucf.edu/reporting-misconduct-and-protection-from-retaliation/

Maine's Public Universities https://www.maine.edu/board-of-trustees/policy-manual/section-402/

Columbia University https://policylibrary.columbia.edu/files/policylib/imce_shared/Non-Retaliation_Policy.pdf

University of Northern Iowa https://policies.uni.edu/1319 
De modo general, estos protocolos o guías que definen la política, tienen elementos comunes. Se reflejan a continuación los más destacables. Por un lado, suelen establecer el deber de informar sobre incumplimientos y cooperar en auditorias e investigaciones. Se señala a los informantes como personas protegidas por el hecho de hacerlo. Se marcan las represalias como violación de obligaciones, valores universitarios y códigos de buena conducta tanto a nivel general como de gestión de recursos humanos. Y, además, se apunta la no colisión con otros protocolos ante otros problemas específicos (v.g. acoso sexual) o regulaciones de evaluación laboral o procedimientos administrativos.

Es habitual ofrecer una definición de lo que se consideran represalias y sus diversas manifestaciones. Por ejemplo, actos (o amenaza de realizarlos) que pueden considerarse como represalias, tales como:

- bloqueo de fondos o recursos,

- descenso de categoría o dificultad/bloqueo de oportunidades de promoción,

- despido y no renovación del empleo,

- hacer evaluaciones negativas del desempeño profesional o académico,

- movilidad a un puesto de menor responsabilidad, traslados,

- observaciones o comentarios ofensivos,

- pérdida de relaciones o aislamiento,

- retiro de facultades delegadas,

- separación de un equipo o proyecto...

Se establecen indicaciones de los mecanismos para la denuncia de tales conductas y se instauran requerimientos a Rectorado y Defensorías u otras agencias internas (en nuestro contexto puede ser la Inspección de Servicios). Por ejemplo, "una persona que considere haber sido objeto de actos de represalia por denunciar presuntos actos indebidos o cooperar con una investigación o una auditoría puede conversar extraoficialmente sobre el tema con la DU". Estas consultas se mantienen en la más estricta confidencialidad, "a menos que la persona interesada autorice expresamente a la DU a que siga impulsando el tema en su nombre".

Se coincide también en señalar requerimientos de verosimilitud para las denuncias: "Una persona que presente un informe por escrito sobre represalias debe fundamentar la denuncia con información fidedigna o documentación que demuestre que: ha denunciado actos indebidos o cooperado en una investigación o una auditoría; como consecuencia de ello ha sido objeto de medidas injustificadas o perjudiciales, y piensa justificadamente que los actos presuntos de represalia se produjeron por haber denunciado actos indebidos 0 por cooperar en una investigación o una auditoría".

Muchas de las organizaciones que tienen protocolos para proteger a los denunciantes (o informadores) establecen también procedimientos "anónimos" para poder hacer la denuncia o aviso de mal comportamiento.

Para asegurar su total protección, las personas pertenecientes a la Universidad o ajenas a ella pueden denunciar una falta de ética empleando el servicio de ayuda/denuncia sobre ética/RSC/ODU de la Organización (en las siguientes direcciones de la web www.universidad.odu.) y/o telefónico gratuito (34- $x \chi x-\chi x \chi-\chi x \chi)$. 
A la hora de identificar al denunciante, en nuestro contexto el principal problema se centra en conciliar:

(a) el derecho del denunciado a acceder al expediente administrativo con

(b) el deber de sigilo de las autoridades y personal al servicio de la Administración Pública,

(c) la protección del denunciado en su seguridad e intimidad,

(d) el carácter público de la información obrante en un órgano administrativo en el contexto de la transparencia,

(e) y, por último, el derecho del denunciado a conocer el origen de los datos que un órgano o entidad someten a tratamiento.

Salvadas las diferencias e idiosincrasias de las distintas universidades y organizaciones, es relativamente asquible observar una visión compartida de las conductas que se quieren respetar, de la protección que se desea ofrecer a las personas que se atreven y dan el paso para realizarlas. Tampoco existen llamativas diferencias en los recursos, procedimientos a los que se insta para concretar esa política y actitud de protección y de inhibición de represalias. No obstante, no era el objetivo principal de este trabajo de reflexión el comparar los protocolos de un modo sistemático y exhaustivo. Esa tarea quizá deba ser abordada como un elemento previo de interés antes de lanzarse a perfilar un protocolo propio o procedimiento articulado con la normativa interna propia en cada universidad. Lo que señalamos aquí es el papel relevante y de oportunidad que las Defensorías Universitarias pueden y deben tener en ello.

\section{Conclusiones}

La investigación desde diferentes perspectivas del comportamiento organizacional viene indicando la presencia de ambientes organizativos y laborales donde las personas en sus diferentes roles se ven atenazados por emociones de temor, miedo, ansiedad, angustia e incluso, en algunos casos, por situaciones de indefensión. En una mayoría de las veces, hay elementos subjetivos y objetivos en la "jungla" organizacional actual para que la prudencia, la reserva, la consideración de los riesgos y la autoevaluación en la toma de decisiones no sean comportamientos descabellados. Unas ciertas "dosis" de las emociones del miedo y las conductas evitativas y preventivas son "normales" y resultan adaptativas en la complejidad e incertidumbres del desarrollo profesional y organizativo de este tiempo. No obstante, la predominancia, la extensión, la permanencia de los efectos del miedo y del silencio que acarrean en la interacción entre personas y organizaciones, ya ha sido cuestionada y puestas de manifiesto como algo disfuncional a muchos niveles humanos, empresariales e institucionales. Las universidades y los campus no están exentos, como organizaciones y comunidades, de los problemas, mecanismos y dinámicas que se observan y han estudiado en otras entidades. Existe ya una acumulación de trabajos sobre problemas y malas prácticas y sobre conductas peligrosas y violentas en el contexto universitario. También sabemos que el problema del comportamiento no ético o de corrupción es algo en pleno afloramiento y de interés en la investigación, denuncia, gestión y formación.

En ese contexto, resulta muy relevante la presentación de quejas y denuncias, la aportación de información sobre comportamientos disfuncionales, no éticos, violentos, corruptos; en definitiva, contrarios a estándares procedimentales, valorativos, 
funcionales, legales, de lo que podríamos enunciar en modo amplio como "justicia organizacional". Sin embargo, los miembros de la organización o de la universidad que se atreven y deciden cumplir con lo que consideran un deber o una aportación a los fines y aspiraciones de la comunidad con la que se identifican y pertenecen. Aquellas personas que deciden romper la "ley del silencio" se encuentran a menudo con poca escucha, atención o un trato no suficientemente diligente, pero peor aún, en algunas ocasiones, con consecuencias indeseables, inmerecidas y con dolorosas represalias. No obstante, cada vez más se está reaccionando contra la que a veces es revictimización o penalización y silenciamiento de lo que es un comportamiento correcto de ciudadanía organizacional. En definitiva, a través de la experiencia de compañías, empresas, y de otras organizaciones como las universitarias podemos ver la intercalación de las guías anti-represalias con otros elementos de la política interna hacia los miembros de la organización y de la comunidad universitaria. La coincidencia, cada vez generalizada, del interés y ventajas que tiene en el control de las conductas disfuncionales y no éticas, el papel de las personas informantes y denunciantes, empuja y promueve un compromiso articulado, explícito y visible de su protección. Los protocolos y guías anti-represalias son buenos instrumentos para cumplirlo.

\section{Referencias}

Andreoli, N. \& Lefkowitz, J. (2009). Individual and Organizational Antecedents of Misconduct in Organizations. Journal of Business Ethics, 85, 309-332. DOI 10.1007/s10551008-9772-6.

Asad, M. \& Al-Dubaisi, A. H. (2008). Barriers to organizational creativity: The marketing executives' perspective in Saudi Arabia. Journal of Management Development, 27(6), 574-599.

ATU Spain - Asociación Para La Transparencia En La Universidad (s.f.). https://atuspain. es/

Ayuso, J. L. (1988). Trastornos de angustia. Barcelona: Martínez Roca.

Bedoya, C. y García-Solarte, M. (2016). Efectos del miedo en los trabajadores y la organización Estudios Gerenciales 32, 60-70. http://www.redalyc.org/pdf/212/21244782006. pdf

Bedoya, C. y Velásquez, A. (2014). Análisis de la incidencia del miedo en la organización desde la perspectiva psicobiológica. Revista Colombiana de Psicología, 23(2), 351-362. doi: 10.15446/rcp.v23n2.38635.

Borraz, M. (2017, 12 de enero). "Tardamos en denunciar acoso en la universidad porquesu estructura feudal nos silenció" https://eldiario.es/sociedad/Tardamos-denunciar-universidad-estructura-silencio_o_600890654.html

Boix Palop, A. (2018), La autonomía universitaria y su proyección en la elaboración de códigos éticos y de buenas prácticas respecto de la actividad investigadora. Dilemata, Revista Internacional de Éticas Aplicadas, 27, 91-114 https://dialnet.unirioja.es/servlet/ articulo? codigo $=6543295$

Casado, R. (2018, 4 mayo). La indefensión aprendida. https://amadag.com/la-indefension-aprendida/

Coget, J., Haag, C. y Gibson, D.E. (2011). Anger and fear in decision-making: The case of film directors on set. European Management Journal, 29, 476-490. $\quad$ https://doi. org/10.1016/j.emj.2011.06.003 
Cornell, D. (2010). Threat Assessment in College Settings. Change. The Magazine of Higher Learning, Jan-Feb., 7-15. DOI: 10.1080/00091380903448997.

https://www. researchgate.net/publication/232886792

Donaghey, J., Cullinane, N., Dundon, T. \& Wilkinson, A. (2011). Reconceptualising employee silence: problems and prognosis. Work Employment Society 25 (1), 51-67. https://doi. org/10.1177/0950017010389239

Einarsen, S. y Hauge, L.J. (2006). Antecedentes y consecuencias del acoso psicológico en el trabajo: una revisión de la literatura. Revista de Psicología del Trabajo y de las Organizaciones, 22(3), 251-273. http://www.redalyc.org/articulo.oa?id=231317121002

European Commision (2018). Proposal for a Directive of the European Parliament and of the Council on the protection of persons reporting on breaches of Union law. Bruselas.

European Parliament \& The Council (2019). Directive (EU) 2019/1937 on the protection of persons who report breaches on Union law. Official Journal of the Europena Union, L205/17. https://eur-lex.europa.eu/legal-content/EN/TXT/PDF/?uri=CELEX:32019L1937\&rid=4 Hay versión es español en https://www.boe.es/doue/2019/305/ L00017-00056.pdf

Fapohunda, T.M. (2016). Organizational silence: predictors and consequences among university academic staff. International Journal for Research in Social Science and Humanities Research, 2(1),83-103

Fløvik, L., Knardahl, S. and Christensen, J.O. (2019). The Effect of Organizational Changes on the Psychosocial Work Environment: Changes in Psychological and Social Working Conditions Following Organizational Changes. Frontiers in Psychology 10:2845. https:// doi.org/10.3389/fpsyg.2019.02845

Fouce, Héctor (Julio 20, 2016) La libre expresión en la universidad en tiempos de miedo y rabia. CTXT. Revista Contexto. 74, https://ctxt.es/es/20160720/Culturas/7294/ universidad-debate-critica-libertad-expresion.htm

Gimpelson, V. y Oshchepkov, A. (2012). Does more unemployment cause more fear of unemployment? Journal of Labor \& Development, 1(6), 1-26. https://doi.org/10.1186/21939020-1-6

Guénin-Paracini, H., Malsh, B. y Marché, A. (2014). Fear and risk in the audit process. Accounting, Organizations and Society, 39, 264-288. https://doi.org/10.1016/j. aos.2014.02.001

Hareli, S., Shomrat, N. \& Biger, N. (2005). The role of emotions in employees' explanations for failure in the workplace. Journal of Managerial Psychology, 20 (8),663-680. https://doi.org/10.1108/02683940510631435

Jara, Y. (2018, 10 de abril). Más de la mitad de las universidades públicas españolas registran casos de acoso. (Reportaje). Pikara, Online Magazine. http://www.pikaramagazine.com/2018/04/mas-de-la-mitad-de-las-universidades-publicas-espanolasregistran-casos-de-acoso/

Jericó, P. (2006). No Miedo: En la empresa y en la vida. Barcelona: Alienta Editorial.

Jericó, P. (2010). No Miedo: una nueva forma de Gestión de Personas. I Congreso Mundial: No Miedo, construyendo la confianza. Newsletter. (2011) https://www.newfield.cl/ newsletters-antiguos/miedo-en-las-organizaciones

Kenny, K., Fotaki, M. \& Vandekerckhove, W. (2020). Whistleblower Subjectivities: Organization and Passionate Attachment. Organization Studies, 41(3) 323-343. DOI: $10.1177 / 0170840618814558$

Keegan, S. M. (2015). The psychology of fear in organizations. How to transform anxiety into wellbeing, productivity and innovation. London: Kogan Page. 
Kriegesmann, B., Kley, T. y Schwering, M. G. (2007). Making organizational learninghappen: The value of 'creative failures'. Business Strategy Series, 8(4), 270-276.

Lindo, J.M., Siminski,P. \& Swensen, I.D. (2018). College Party Culture and Sexual Assault. American Economic Journal: Applied Economics, 10(1), 236-265.https://doi.org/10.1257/ app.20160031

Leymann, H. (1990). Mobbing y Terror Psicológico en los lugares de Trabajo. Violence and Victims, 5 (2) 119-126. Trad. S. Navarrete. México DF (2009)

Martínez-Jurado, M. (March 13, 2017). La psicología del miedo en los entornos laborales www. cincodias.elpais.com/cincodias/2017/03/13/economia/1489426923 028996.html

Mateus, S., Veiga, A.M., Costa, P. \& Martins, M.J.D. (2014). Cyberbullying: The hidden side of college students. Computers in Human Behavior, 43, 167-182

http://dx.doi.org/10.1016/j.chb.2014.10.045

Milliken, F. J. y Morrison, E. W. (2003). Shades of silence: Emerging themes and future directions for research on silence in organizations. Lournal of Management Studies, 40(6), 1563-1568.

Milliken, F. J., Morrison, E. W. y Hewlin, P. (2003). An exploratory study of employee silence: Issues that employees don't communicate upward and why. Journal of Management Studies, 40(6), 1453-1476.

Mesmer-Magnus, J.R. \& Viswesvaran, C. (2005). Whistleblowing in Organizations: An Examination of Correlates of Whistleblowing Intentions, Actions, and Retaliation. Journal of Business Ethics, 62, 277-297. DOI: 10.1007/s10551-005-0849-1 https://www. researchgate.net/publication/227316158

Morrison E.W., See, K.E. \& Pan, C. (2015). An Approach Inhibition Model of Employee Silence: The Joint Effects of Personal Sense of Power and Target Openness. Personnel Psychology, 68 (3), 547-580. https://doi.org/10.1111/peps.12087

OECD (2016), Committing to Effective Whistleblower Protection, OECD Publishing, Paris. http://dx.doi.org/10.1787/9789264252639-en. Disponible en https://www. oecd-ilibrary.org/governance/committing-to-effective-whistleblower-protection_9789264252639-en

Pan American Health Organization (2009). Política de protección contra las represalias en casos de denuncia de actos indebidos o de cooperación en una investigación o una auditoría. Tomado de https://www.paho.org/hq/dmdocuments/2013/ProtectAgainstRetaliationSPANISH.pdf

Pohler, D.M. \& Luchak, A.A. (2014). Balancing Efficiency, Equity, and Voice: The Impact of Unions and High-Involvement Work Practices on Work Outcomes ILR Review, 67(4), 1063-1094 DOI: 10.1177/0019793914546295.

Polo, S. (2015, 27 de enero). Las quejas del universitario, David contra Goliat. https://www. elmundo.es/espana/2015/01/27/54c7f71222601d7c638b4576.html

Quirós García, E. (2019). El mobbing académico, fenómeno ignorado y de responsabilidad conjunta: estudio de caso en una universidad estatal en Costa Rica. Repertorio Americano, 29,185-200. http://dx.doi.org/10.15359/ra.1-29.12

Ryan, K. y Oestreich, D. K. (1991). Driving fear out of the workplace: How to overcome the invisible barriers to quality, productivity, and innovation. San Francisco: Jossey-Bass.

Rudman, L. A., Borgida, E. \& Robertson, B. A. (1995). Suffering in Silence: Procedural Justice Versus Gender Socialization Issues in University Sexual Harassment Grievance Procedures. Basic And Applied Social Psychology, 17(4), 519-541. DOI: 10.1207/ s15324834basp1704_6 https://www.researchgate.net/publication/232464191

Scarnati, J. T. (1998). Beyond technical competence: Fear — banish the beast. Leadership \& 
Organization Development Journal, 19(7), 362-365.

Sierra, Juan Carlos; OrtegaII, Virgilio; Zubeidat, Ihab (2003). Ansiedad, angustia y estrés: tres conceptos a diferenciar Revista Mal Estar e Subjetividade versão On-line 3 (1). http:// pepsic.bvsalud.org/scielo.php?script=sci arttext\&pid=S1518-61482003000100002

Sincoff, M.Z., Slonaker, W.M. \& Wendt, A.C. (2006). Retaliation: The form of 21st century employment discrimination. Business Horizons, 49, 443-450. http://dx.doi. org/10.1016/j.bushor.2006.02.005

Urda, J. y Loch, C. H. (2013). Social preferences and emotions as regulators of behavior in processes. Journal of Operations Management, 31, 6-23. https://doi.org/10.1016/j. jom.2012.11.007

Vahtera, J., Kivimaki, M., Pentti, J., Linna, A., Virtanen, M., Virtanen, P., et al. (2004). Organisational downsizing, sickness absence, and mortality: 10-town prospective cohort study. British Medical Journal, 328(7439), 555. DOI: $10.1136 / \mathrm{bm}-$ j.37972.496262.0D

Vila, J. (1984). Técnicas de reducción de ansiedad. En J. Mayor \& F. J. Labrador (Eds.), Manual de Modificación de conducta (pp. 229- 264). Madrid: Alhambra.

Villasante, Mar (Febrero 1, 2017). Acoso, plagio o agresión sexual: así se 'compra' el silencio en la Universidad.http://www.elmundo.es/f5/campus/2017/02/01/5890d1562260 $1 \mathrm{do6} 698 \mathrm{~b} 4687 . \mathrm{html}$

Suárez, G. (1997). Tres expertos en calidad. El miedo en la organización. Asturias (España): Asturias Bussines School.

Sumanth, J.J., Mayer, D.M. \& Kay V.S. (2011). Why good guys finish last: The role of justification motives, cognition, and emotion in predicting retaliation against whistleblowers. Organizational Psychology Review 1 (2), 165-184. https://doi. org/10.1177/2041386611398283

Thongsukmag, J. (2003). Fear in the Workplace: The Relationships among Sex, Self-efficacy, and Coping Strategies. Doctoral Dissertation. Virginia Polytechnic Institute and State University. https://vtechworks.lib.vt.edu/handle/10919/28454

Universidad para la Paz (2017). Política de protección contra represalias por informar faltas de conducta y por cooperar con auditorías o investigaciones debidamente autorizadas. Disponible en https://www.upeace.org/files/Legal Docs/Politica de proteccion contra represalias por informar faltas de conducta y por cooperar con auditorias o investigaciones debidamente autorizadas.pdf

Villasante, M. (2017, 1 de febrero). Acoso, plagio o agresión sexual: así se 'compra' el silencio en la Universidad. https://elmundo.es/f5/campus/2017/02/01/5890d15622601d0669 8b4687.html

Weisenbach, E., Hughes, S. \& Hertz, G. (2011). A model for assessment and mitigation of threats on the college campus. Journal of Educational Administration, 49(1), 76-94. https://doi.org/10.1108/09578231111102072

Zoghbi- Manrique, P. (2006).Fear in organizations: Does intimidation by formal punishment mediate the relationship between interactional justice and workplace internet deviance? Journal of Managerial Psychology, 21(6),580-592. https://doi. org/10.1108/02683940610684418 